\title{
Increased Fibronectin Expression in Sturge-Weber Syndrome Fibroblasts and Brain Tissue
}

\author{
ANNE M. COMI, PIPER HUNT, MARQUIS P. VAWTER, CARLOS A. PARDO, \\ KEVIN G. BECKER, AND JONATHAN PEVSNER
}

\begin{abstract}
From the Departments of Neurology [A.M.C., C.A.P.], Genetics [P.H.], Pathology [C.A.P.], and Neuroscience [J.P.], Johns Hopkins University School of Medicine, Baltimore, MD 21287, U.S.A.; the Department of Neurology [J.P.], Kennedy Kreiger Institute, Baltimore, MD 21205, U.S.A.; the DNA Array Unit [K.G.B.], National Institute on Aging, National Institutes of Health, Baltimore, MD 21224, U.S.A.; and the Department of Psychiatry [M.P.V.], University of California, Irvine, CA 92697-1675, U.S.A.
\end{abstract}

\begin{abstract}
Sturge-Weber syndrome (SWS) is a neurocutaneous disorder that presents with a facial port-wine stain and a leptomeningeal angioma. Fibronectin expression regulates angiogenesis and vasculogenesis and participates in brain tissue responses to ischemia and seizures. We therefore hypothesized that abnormal gene expression of fibronectin and other extracellular matrix genes would be found in SWS brain tissue and SWS port-wine skin fibroblasts. Fibronectin gene and protein expression from port-wine-derived fibroblasts were compared with that from normal skin-derived fibroblasts of four individuals with SWS using microarrays, reverse transcriptasePCR, Western analysis, and immunocytochemistry. Fibronectin gene and/or protein expression from eight SWS surgical brain samples was compared with that in two surgical epilepsy brain samples and six postmortem brain samples using microarrays, reverse transcriptase-PCR, and Western analysis. The gene expression of fibronectin was significantly increased $(p<0.05)$ in the SWS port-wine-derived fibroblasts compared with that of fibroblasts from SWS normal skin. A trend for increased protein levels of
\end{abstract}

\section{ABSTRACT}

fibronectin in port-wine fibroblasts was found by Western analysis. No difference in the pattern of fibronectin staining was detected. The gene expression of fibronectin was significantly increased $(p<$ 0.05 ), and a trend for increased fibronectin protein expression was found in the SWS surgical brain samples compared with the postmortem controls. These results suggest a potential role for fibronectin in the pathogenesis of SWS and in the brain's response to chronic ischemic injury in SWS. The reproducible differences in fibronectin gene expression between the SWS port-wine-derived fibroblasts and the SWS normal skin-derived fibroblasts are consistent with the presence of a hypothesized somatic mutation underlying SWS. (Pediatr Res 53: 762-769, 2003)
Abbreviations
SWS, Sturge-Weber syndrome
ECM, extracellular matrix
RT-PCR, reverse transcriptase-PCR

Sturge-Weber syndrome (SWS) is a neurocutaneous disorder that classically presents with a facial port-wine stain, in the ophthalmic distribution of the trigeminal nerve, associated with an ipsilateral leptomeningeal angioma. Children and adults with SWS often develop progressive neurologic problems, including difficult-to-control seizures, migraines, stroke-like episodes, mental retardation, and hemiparesis. Treatment for SWS is largely symptomatic and directed at the control of seizures with anticonvulsants or surgery $(1,2)$.

Received April 5, 2002; accepted November 13, 2002.

Correspondence: Dr. Anne Comi, Department of Neurology, Division of Pediatric Neurology, Johns Hopkins University School of Medicine, 123 Jefferson Bldg. $600 \mathrm{~N}$. Wolfe Street, Baltimore, MD 21287; e-mail: acomi@jhmi.edu

Supported by grants from the Sturge-Weber Foundation, NINDS (K12NS01696), and the Developmental Disabilities Mental Retardation Research Center (HD24061). M.P.V. was supported by the William Lion Penzner Foundation.

DOI: 10.1203/01.PDR.0000058921.54071.19
SWS occurs almost entirely sporadically and with equal frequency in the sexes (3). The genetic or environmental/ prenatal factors resulting in the disorder are not known. The localized abnormalities of blood vessel development and function affecting the facial skin, eye, and brain suggests a developmental disruption that occurs in the first trimester of pregnancy (4). Somatic mutation has been cited as the probable cause of SWS, given the localized, asymmetric abnormality of blood vessel formation (5). However, the putative mutation is unknown, and other molecular mechanisms are possible. No animal model for SWS exists at this time.

Histologic studies of SWS brain angiomas have revealed large tortuous and abnormal venous structures in the thickened leptomeninges. The underlying brain tissue may be atrophic and display neuronal loss, astrogliosis, dysgenic cortex, and calcification in the cortical layers (6). The cortical vessels 
underlying the meningeal angioma are thin-walled, narrowed by hyalinization and subendothelial proliferation $(3,7)$, and increased in number (8).

The basal lamina separating vascular endothelial cells from the surrounding connective tissue is composed of numerous glycoprotein and proteoglycan extracellular matrix (ECM) molecules, including fibronectin, laminin, and tenascins (9). The ECM has critical roles in neovascularization during development $(10,11)$. Fibronectin is the prototypic ECM molecule and has key roles in regulating angiogenesis and vasculogenesis, as well as brain tissue responses to ischemia and seizures. Fibronectin 1 is one of the most common splice variants $(12,13)$.

SWS is a disorder of abnormal vascular development, and previous literature has reported differences in the staining patterns of several ECM molecules in port-wine skin tissue (14). We therefore hypothesized that abnormal gene expression of fibronectin would be found in SWS brain tissue and SWS port-wine skin fibroblasts. This study analyzes fibronectin gene and protein expression of fibroblasts derived from port-wine stains and normal skin of four subjects with SWS, as well as that of SWS cortical brain tissue and controls.

\section{METHODS}

Skin biopsy samples and fibroblast cultures. Four individuals with SWS were recruited for tissue donation through the Sturge-Weber Foundation. Clinical information was simultaneously solicited using a brief questionnaire. Punch biopsies were obtained from port-wine skin and normal skin by dermatologists. The Institutional Review Board of Johns Hopkins approved the protocol, and all participants gave informed consent. Fibroblast cultures were initiated from each of the eight skin biopsies. Cells were at passage 6-7 for the mRNA isolation and at passage 9-10 for the protein isolation. Karyotyping was performed on all four SWS port-wine-derived fibroblast cell lines at passages ranging from 6 to 8 .

Table 1 details the clinical information gathered regarding the four SWS subjects from whom skin biopsies were taken. The ages ranged from 5.5 to $35 \mathrm{y}$, and there were three female subjects. The normal and port-wine skin biopsies were taken from a variety of skin regions, and no consistent differences in the location were found between normal and port-wine sites. Three subjects had had no previous laser treatment to the biopsied area of the port-wine stain.
Brain tissue samples. Surgical cortical brain tissue, pathologic reports, and clinical data were obtained directly from the treating institutions, the Maryland Brain Bank, or the Harvard Brain Bank. For the microarray analysis, RNA from two SWS brain tissue samples was compared with that from two surgical epilepsy controls. For the PCR studies, cDNA from five SWS brain samples was compared with four postmortem control samples. For the Western analyses, homogenates from six SWS cortical brain samples were compared with five postmortem control brain samples.

An effort was made to obtain matches when possible; to obtain a range of ages, sex, and brain regions for the postmortem controls used; and to take into account significant discrepancies between the two groups (SWS and controls) in the analysis of the data. Table 2 outlines the clinical data from the eight SWS brain samples, the two epilepsy samples, and the six postmortem control samples and indicates which samples were used for the various assays/studies performed. In the reverse transcriptase-PCR (RT-PCR) analysis, the mean age \pm SD of the five SWS subjects was $3.2 \pm 3.8 \mathrm{y}$ and of the four controls was $11.8 \pm 9.1 \mathrm{y}$. For the Western analysis, the mean age of the six SWS subjects was $5.2 \pm 5.7 \mathrm{y}$ and for the five controls was $6.8 \pm 7.1 \mathrm{y}$.

Pathology reports were received from the treating institutions and reviewed for all surgical brain specimens to confirm pathologic diagnosis. Visual inspection of the SWS cortical samples revealed large vascular structures on the outer surface. In addition, cryostat sections were obtained from all of the postmortem and surgical brain samples. These sections were stained with hematoxylin and eosin and reviewed by a neuropathologist. All tissue was found to be cortical and in suitable condition for the analyses.

$\boldsymbol{R N A}$ isolation. RNA was isolated by RNeasy prep (Quiagen) from a T75 flask of each fibroblast cell line. RNA was isolated from the brain samples using TRIzol (GIBCO/BRL). RNA quality was assessed by the $\mathrm{A}_{260} / \mathrm{A}_{280}$ ratio and was between 1.9 and 2.0 from the RNeasy preparations and 1.8 and 1.9 from the TRIzol preparations (data not shown). RNA integrity was confirmed on all RNA samples by electrophoresis on an ethidium-stained agarose gel (data not shown).

cDNA array hybridization and analysis. The microarray analysis of the fibroblast RNA was performed using National Institutes of Health neuroarrays as described in a published protocol (15). Eight micrograms of total human fibroblast RNA

Table 1. Clinical characteristics of skin biopsies taken for SWS fibroblast cell lines

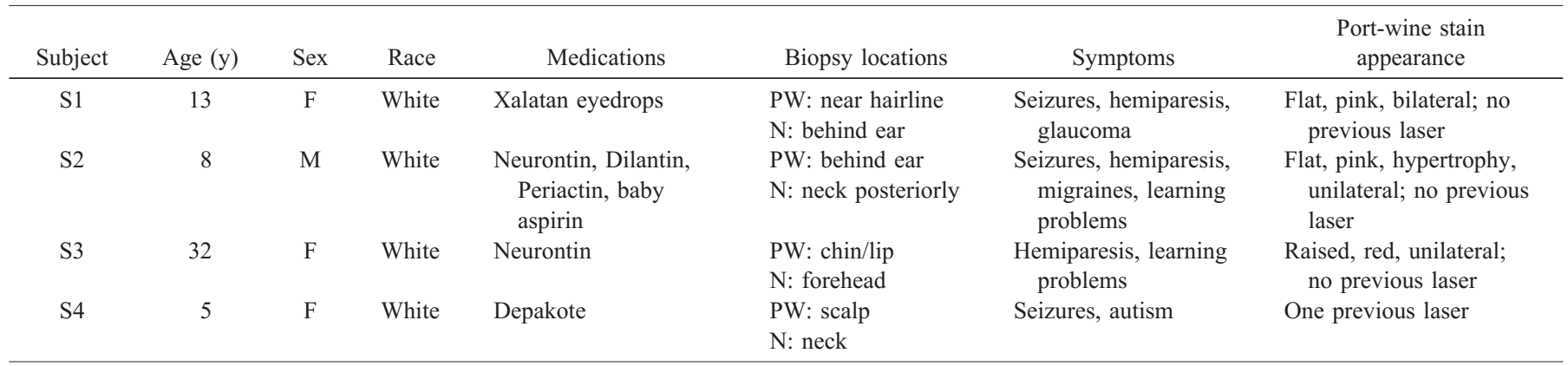

PW, port-wine skin biopsy; N, normal skin biopsy. 


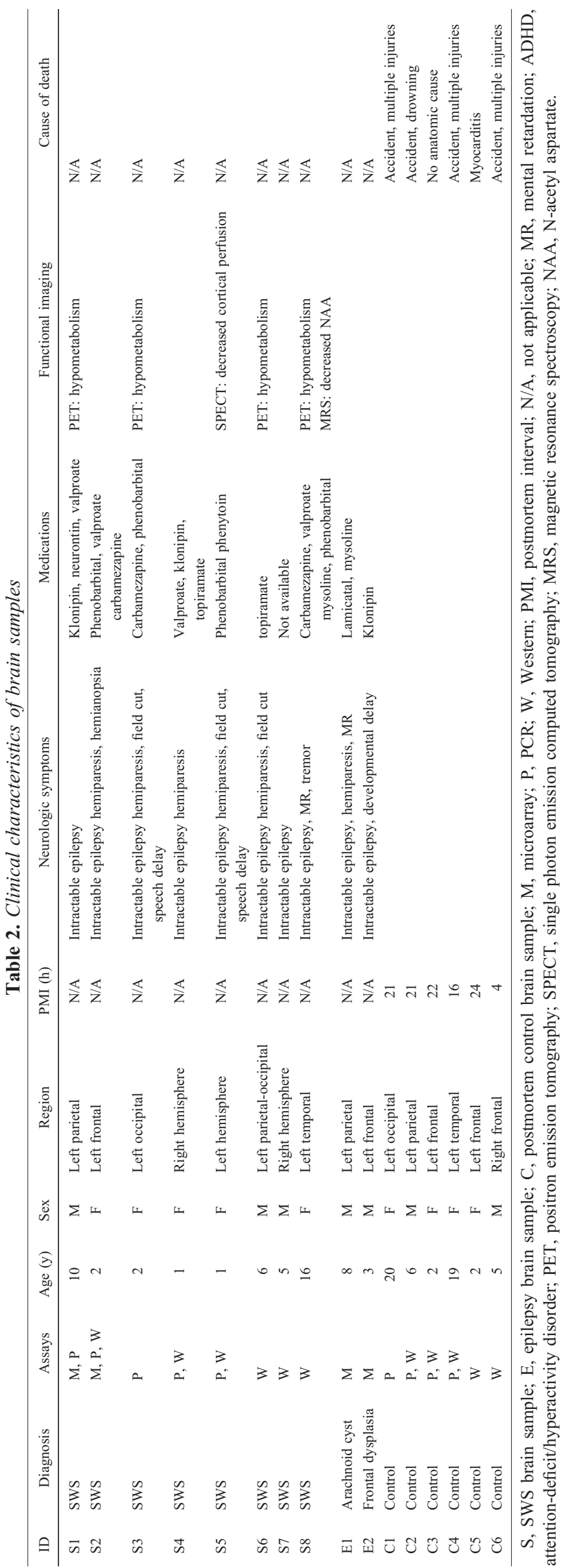

was labeled in the reverse-transcription reaction mixture. Two separate labeling reactions and subsequent hybridizations were performed using the same eight RNA samples. The National Institutes of Health filters have spotted on them 1128 genes with each cDNA spotted twice, one on each half of the filter. A few genes are present in duplicate and are spotted four times on the same filter.

Images obtained from hybridization of the fibroblast RNA probes to a total of 14 filters (one pair of filters was removed from the analysis as one of the pair had dried out during hybridization) were gridded and the intensity values obtained using Image Quant software. Intensity values were normalized using global normalization. The consistency of the National Institutes of Health microarray results was assessed with a Pearson's correlation comparing the two hybridizations of each gene per filter, and the two separate labelings were performed. For each RNA sample, all of the individual data points for each gene were averaged, and the overall averages then were calculated ( $n=4$ port-wine and $n=4$ normal). Fold regulation of gene expression was assessed with ratios of the overall averaged normalized port-wine sample to averaged normal sample signal intensity. A paired two-tailed $t$ test was used to calculate $p$ values comparing the average normalized intensity values. A conservative Bonferroni correction was performed as a test of repeated measures.

Microarray analysis of the two pairs of brain RNA samples (each comparing an SWS brain sample with an epilepsy brain sample) was performed with UniGEM V2 fluorescence arrays (Incyte Genomics, St. Louis, MO), which has 9374 sequenceverified human cDNAs. mRNA was isolated from the brain total RNA using an Oligotex kit (Quiagen) according to the manufacturer's protocol. Microarray hybridization was performed at Incyte Genomics as previously described (16).

The Incyte data were analyzed for expression ratios of $\geq 1.8$-fold differences that were consistent in both comparisons. In addition, a normalization process designated SNOMAD (17), which calculates a local SD in $\log$ (ratio) values across a range of expression values, was performed. Genes that had $z$ scores consistently greater than 2 in both brain comparisons were identified.

$\boldsymbol{R T}$-PCR. Primers used were as follows: fibronectin, forward 5'-TCCAATCCAGAGGAACAAGCATG-3', reverse 5'TTGGTTGGCTGCATATGCTTTCC-3'; hexabrachion, forward 5'-TTGGAGGGACCACTGGGTGAGAG-3', reverse 5'-CCTACCСCTCTCCCATCCCAGAG-3'.

Five micrograms of each total RNA sample was reversetranscribed using SuperScript II (LTI) protocol for first strand cDNA synthesis. RT-PCR was performed by LightCycler PCR thermo-cycler (Roche), and PCR product was quantified on an ethidium-stained gel as previously described (16), with normalization to actin. A paired, one-tailed $t$ test was used to assess differences in fibronectin expression between SWS portwine-derived fibroblasts and SWS normal skin-derived fibroblasts. An unpaired, one-tailed $t$ test was used to assess differences in the expression of fibronectin and hexabrachion in SWS brain samples versus controls.

Western blot analysis. Fibroblast protein samples were isolated at subconfluence $(70-90 \%)$ at passages $9-10$ from all 
eight cell lines. Lysates were collected in $1 \mathrm{~mL}$ of protein loading buffer $\left(5.2 \mathrm{~mL} \mathrm{H}_{2} \mathrm{O}, 2 \mathrm{~mL}\right.$ of $1 \mathrm{M}$ Tris- $\mathrm{HCl}, 17 \mathrm{~mL}$ of glycerol, $3.2 \mathrm{~mL}$ of $20 \% \mathrm{SDS}, 1.6 \mathrm{~mL}$ of $\beta$-mercaptoethanol, and $3 \mathrm{~mL}$ of $1 \%$ brophenol blue), sonicated, denatured, and vortexed. The sample was centrifuged at 14,000 rpm for $5 \mathrm{~min}$, and $700 \mu \mathrm{L}$ of supernatant was saved. The difference in fibronectin protein levels between the SWS port-wine and SWS normal lysates was assessed with a paired, one-tailed $t$ test.

Protein was isolated from brain samples by homogenization in $1 \times$ PBS buffer with protease inhibitors [protease inhibitor cocktail (Sigma Chemical Co.), Calpain I and Calpain II (Calbiochem), and AEBSF (Roche)]. Western blots were performed on whole homogenates (as significant portions of fibronectin were in the pellet after spinning at $2300 \mathrm{rpm}$ for 10 min; data not shown). The protein concentrations were determined by the protein assay of Bradford (18). Twenty micrograms of each brain sample was loaded onto a 4-20\% SDS polyacrylamide gel (ISC BioExpress), and Western analysis was performed according to previously described standard techniques (16). A reference sample (sample C5) was electrophoresed on every gel so that results from individual gels could be compared. Bands were quantified by measuring mean signal density using NIH Image analysis software and standardized to actin band intensity measured from the same protein samples. Differences in fibronectin and hexabrachion expression between SWS and control brain samples were assessed with unpaired, one-tailed $t$ tests.

Primary antibodies were used at the following dilutions: anti-fibronectin antibody (BD Transduction Labs, \#F 14420) 1:1000 dilution; anti-hexabrachion antibody (Neomarkers, \#MS 128 P1) 1:67 dilution; anti-actin antibody (Sigma Chemical Co., \#A2066) 1:1000. Secondary antibodies (Jackson ImmunoResearch Labs) were used at dilutions ranging from 1:1000 to 1:3000 depending on the primary antibody.

Immunocytochemistry and fluorescence microscopy. Fibroblasts were fixed on coverslips in 4\% paraformaldehyde in PBS for 5 min in $1 \%$ saponin in PBS. Cells were blocked for $20 \mathrm{~min}$ in $2 \%$ goat serum in PBS before 60 min of incubation with monoclonal fibronectin antibody (BD Transduction Labs) at 1:100 dilution. Coverslips were washed in PBS and incubated $30 \mathrm{~min}$ with rhodamine-conjugated donkey anti-mouse antibody at 1:50 dilution. Cells were viewed with a $100 \times$ oil objective lens on a Zeiss Axioplan microscope, and images were captured with an AxioCam digital camera and the AxioVision 2.0 imaging system (Zeiss).

\section{RESULTS}

Table 3 summarizes the results of these studies and compares the findings in the SWS fibroblast and brain samples that are described in detail below.

Karyotyping results. All four SWS-derived port-winederived fibroblast cell lines had normal karyotypes without evidence of clonal chromosomal abnormalities.

Fibroblast microarray results. The Pearson's coefficient $r$ ranged from 0.930 to 0.995 for comparisons of each gene spotted twice on the 14 blots analyzed. The reproducibility between the two separate labelings was likewise assessed with $r$ ranging from 0.919 to 0.971 . The full microarray data sets from these experiments can be found at pc190-10.kennedykrieger.org/microarraydata/.

Fibronectin 1 was consistently increased in each of the four pairs of port-wine fibroblasts compared with the normal fibroblasts. The overall average normalized fibronectin 1 gene expression value demonstrated a 1.4-fold increase ( $p=0.009$; Fig. 1) in the port-wine samples. Although fibronectin expression reached nominal significance at $p<0.01$, after a conservative Bonferroni correction, this value was not significant. mRNAs encoding other ECM molecules, including laminin, hexabrachion, and multiple $\alpha$ collagen chains (types VI, XI, $\mathrm{XIV}, \mathrm{XV}$, and $\mathrm{XVI}$ ), were not found to be significantly regulated.

Fibroblast PCR results. A 2-fold increase in fibronectin expression was found in the port-wine fibroblasts by PCR $(p=$ 0.03 ; Fig. 2). As predicted from the microarray data, the expression of hexabrachion in the fibroblast samples was not regulated based on PCR analysis (data not shown).

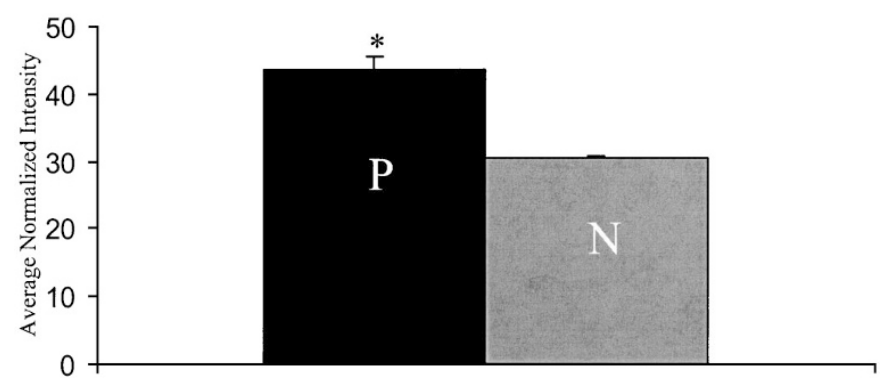

Figure 1. Fibronectin 1 microarray gene expression results. Graph compares averaged normalized intensity values $( \pm$ SEM) from four pairs of SWS portwine $(\mathrm{P})$ and SWS normal (N) fibroblasts. A 1.4-fold increase in fibronectin 1 expression $\left({ }^{*} p<0.01\right)$ was found in the SWS port-wine fibroblasts.

Table 3. Summary of fibronectin expression in SWS port-wine fibroblasts and brain tissue

\begin{tabular}{lll}
\hline & \multicolumn{1}{c}{ Fibroblasts* } & \multicolumn{1}{c}{ Brain tissue $\dagger$} \\
\hline Microarray gene expression & $\uparrow$ Fibronectin 1 (1.4-fold) $\ddagger$ & $\uparrow$ Fibronectin 1 (2.5, 1.9-fold) \\
RT-PCR gene expression & $\uparrow$ Fibronectin 1 (2.0-fold) $\ddagger$ & $\uparrow$ Fibronectin 1 (2.7-fold) $\$$ \\
Western protein expression & $\uparrow$ Fibronectin (1.3-fold)§ & $\uparrow$ Fibronectin (1.7-fold) \\
\hline
\end{tabular}

* Compares fibronectin expression in SWS port-wine skin-derived fibroblasts with SWS normal skin derived fibroblasts from same four individuals with SWS.

$\dagger$ Compares fibronectin expression in SWS cortical tissue with epilepsy cortex (microarrays) or with postmortem cortical tissue (RT-PCR and Western).

$\ddagger$ Statistically significant differences $p<0.05$.

$\S$ Trend. 
Fibroblast Western and immunofluorescence results. Western blot analysis of fibroblast protein isolates revealed a consistent increase in fibronectin such that for all four pairs the protein level of fibronectin was higher (average 1.34-fold) in the port-wine-derived cultures than in the normal skin-derived cultures (Fig. 3). These results approached but did not reach statistical significance, however. Immunofluorescence assays did not demonstrate any consistent differences in the antifibronectin staining pattern (data not shown).

Brain microarray results. The full microarray data sets from these experiments can be found at pc190-10.kennedykrieger. org/microarraydata/. Analysis of expression ratios $\geq 1.8$ or $\leq-1.8$ in both brain array comparisons revealed that the expression of fibronectin 1 (ratios 2.5 and 1.9) and hexabrachion (ratios 2.0 and 1.7) were consistently increased in the SWS cortical brain tissue compared with the surgical epilepsy brain tissue. When the data sets were normalized by SNOMAD to generate $z$ scores, both fibronectin $1(z$ scores $=5.9$ and 6.2) and hexabrachion $(z$ scores $=4.4$ and 4.9$)$ had $z$ scores consistently greater than 2 , indicating significantly increased gene expression in the context of the entire data set. In addition, SNOMAD normalization of the brain microarray data revealed that expression levels of collagen type $1, \alpha 1$ ( $z$ scores $=2.5$ and 3.6), and nidogen $(z$ scores $=2.3$ and 3.0) were also significantly increased. Glial acidic fibrillary protein expres- sion was also increased in the two comparisons with ratios of 4.0 and 2.1 and $z$ scores of 57.5 and 10.2. Genes encoding other ECM molecules that were screened on the Incyte arrays, including laminin and other collagen chains, were not regulated in their expression.

Brain RT-PCR results. RT-PCR with cDNA from five SWS brain tissue samples and four control brain samples confirmed the increase in fibronectin (3.2-fold up-regulation; $p=0.01$ ) and hexabrachion mRNA expression (5.8-fold up-regulation; $p$ $=0.002$; Fig. 4). In both cases, this relationship was unchanged when the two oldest samples (postmortem control samples $\mathrm{C} 4$ and $\mathrm{C} 1$ ) were removed from the analysis (fibronectin: 2.0-fold increase; hexabrachion: 4.7-fold increase). There was a weak negative correlation between the subject's age and the fibronectin and hexabrachion levels $(r=-0.62$ and -0.52 , respectively) that disappeared when the oldest subject samples $\mathrm{C} 4$ and $\mathrm{C} 1$ were removed from the analysis $(r=-0.06$ and -0.04 , respectively).

Brain Western blot results. Western blot analysis of fibronectin protein levels in the six SWS surgical brain samples compared with the five postmortem controls demonstrated a trend for a 1.7-fold increase in fibronectin that approached but did not reach statistical significance (Fig. 5). A trend for a 1.4-fold increase in the protein levels of hexabrachion was
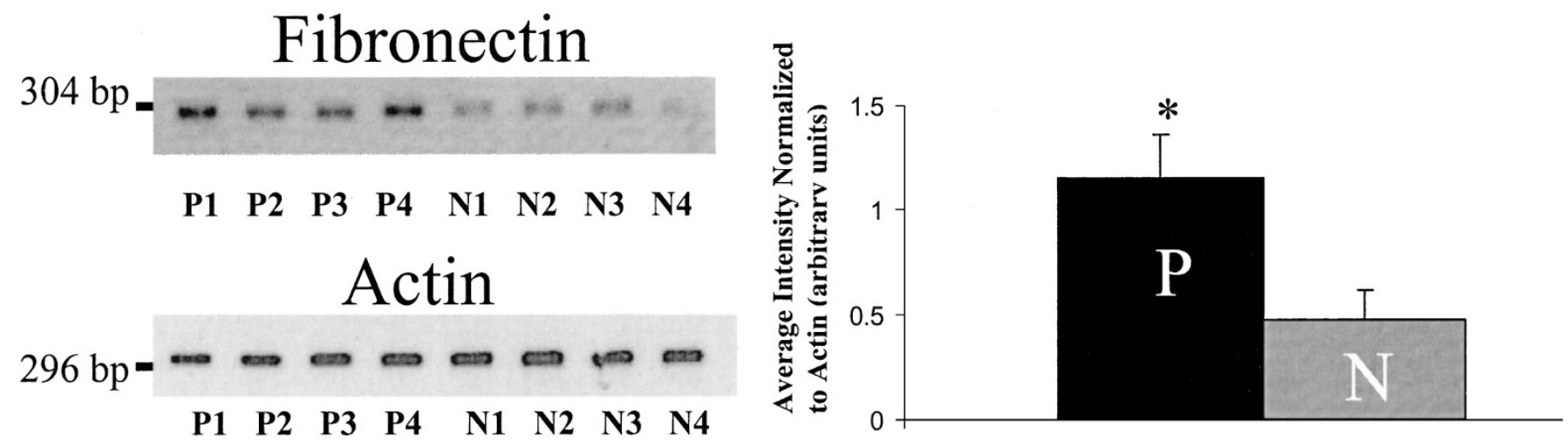

Figure 2. Fibroblast RT-PCR results. The average fibronectin gene expression ( \pm SEM) in SWS port-wine $(\mathrm{P})$ and SWS normal (N) fibroblasts normalized to actin expression is compared. There was a 2-fold increase in fibronectin $(p=0.03)$ expression in the SWS port-wine fibroblasts.

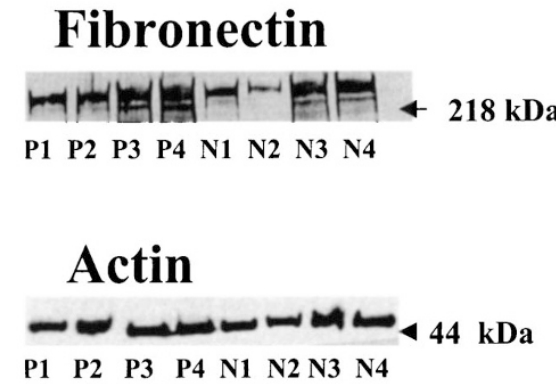

Figure 3. Fibroblast Western blot results. Fibronectin protein levels ( \pm SEM) from SWS port-wine $(\mathrm{P})$ and SWS normal (N) fibroblasts normalized to actin levels demonstrated a trend for a consistent increase in fibronectin protein expression in the port-wine-derived samples. 

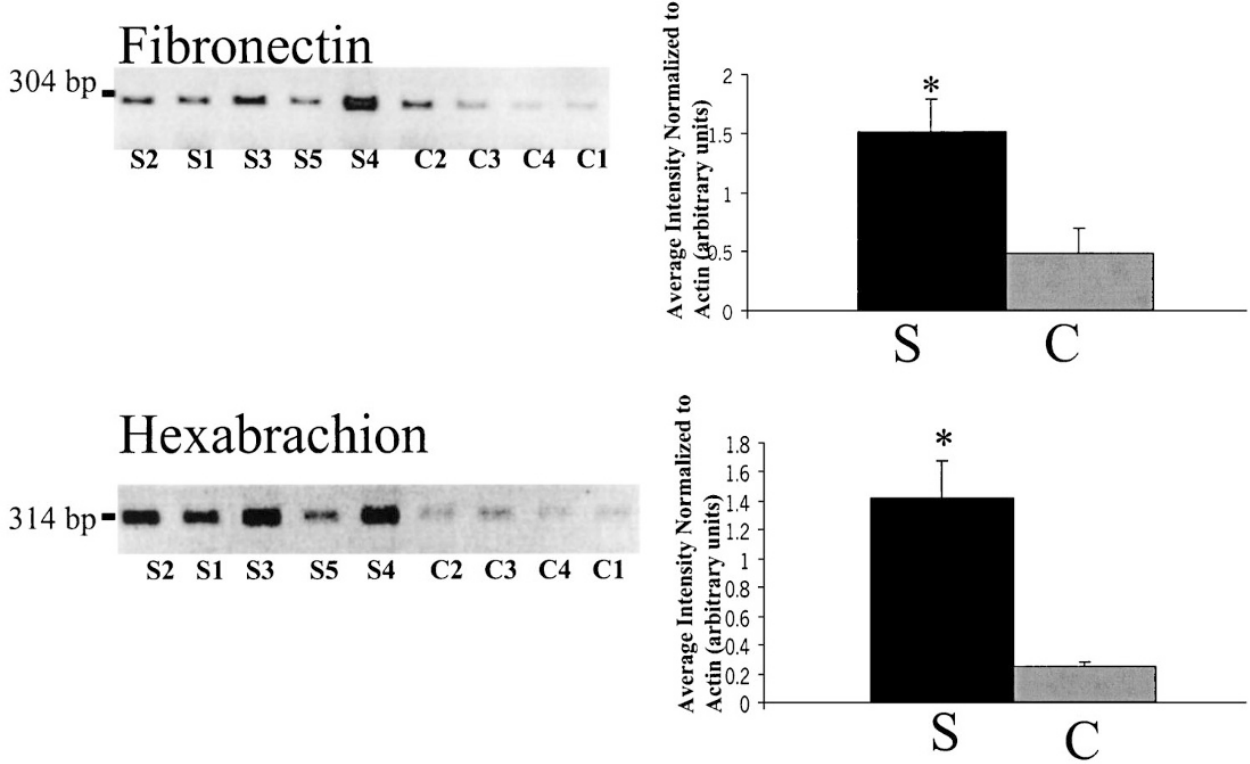

\section{Actin}

$\begin{array}{llllllllllll}\text { S2 } & \text { S1 } & \text { S3 } & \text { S5 } & \text { S4 } & \text { C2 } & \text { C3 } & \text { C4 } & \text { C1 }\end{array}$

Figure 4. Brain RT-PCR results. Fibronectin and hexabrachion gene expression ( \pm SEM) in five surgical SWS cortical brain samples (S) were compared with that in four postmortem control cortical samples $(C)$. Increased gene expression of fibronectin $(p<0.05)$ and hexabrachion $(p<0.005)$ was found in the SWS brain samples.
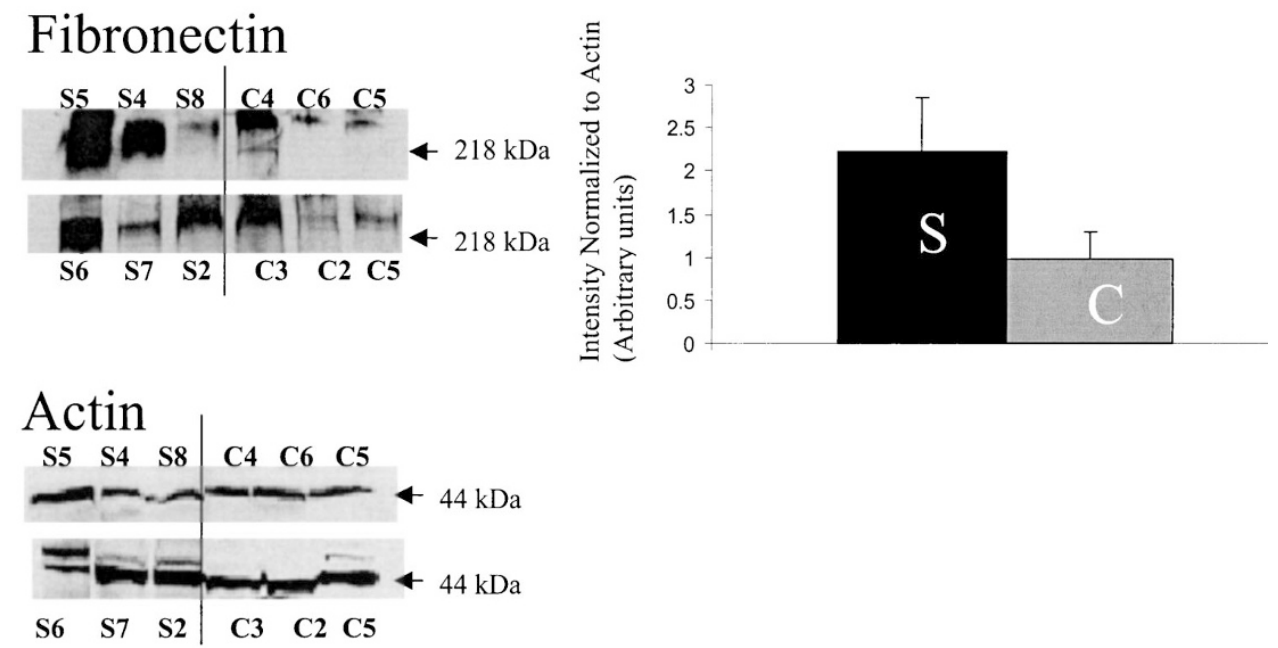

Figure 5. Brain Western blot results. Fibronectin and actin protein expression in six surgical SWS cortical brain samples (S) compared with that in five postmortem controls (C). Error bars indicate SEM. A trend for an increase in fibronectin protein levels was found in the SWS samples.

found in the SWS brain samples compared with the controls (data not shown).

\section{DISCUSSION}

SWS is a unique human model of chronic brain ischemia and epilepsy. Functional brain imaging has demonstrated decreased glucose metabolism and hypoperfusion of affected cortex (19, 20). It is hypothesized that the lack of normal cortical vessels interacting with the overlying angioma produces stasis and thrombosis, resulting in chronic ischemia of cortical tissue
(21). Global brain ischemia is known to stimulate angiogenesis (22), and secondary vascular proliferation has been suggested to occur in SWS (8). However, the extent to which angiogenesis plays a role in SWS neurodegeneration and pathologic changes is unclear.

In fibroblasts derived from the port-wine skin of individuals with SWS, fibronectin gene expression was consistently increased over that in fibroblasts from normal skin of the same individuals with SWS. In addition, we found a trend for increased protein expression that was consistent in all four 
pairs of SWS normal and port-wine fibroblasts. Our interpretation of these data is that the port-wine-derived fibroblasts likely have a somatic mutation that alters cellular function, including an effect of elevated fibronectin gene expression. Isolation of the fibroblast mRNA at culture passage 6-7 makes it unlikely that that the port-wine fibroblasts continued to have altered patterns of gene expression as an artifact of their isolation from abnormal skin tissue samples. If rather the consistent difference in gene expression results from a somatic mutation, then abnormal expression of fibronectin by mutated perivascular fibroblasts could contribute to abnormal development and innervation of blood vessels in SWS. Normal karyotypes, although unrevealing, do not negate the possibility of a somatic mutation in SWS. In addition, angiogenesis studies with SWS port-wine fibroblasts could elucidate further the pathogenic processes involved in SWS.

The increased SWS brain expression of fibronectin, hexabrachion, and glial acidic fibrillary protein, however, probably results from a response of the brain to chronic ischemia. Increased fibronectin expression may contribute to blood vessel proliferation and brain degeneration in SWS. We included surgical epilepsy brain samples to control for the effect of repeated seizures and anticonvulsants on gene expression, and thus the increased fibronectin expression is likely due, at least in part, to the brain's response to chronic brain hypoxia.

It is important to note some limitations in the data presented here. The fibroblast protein analysis performed did not include measurement of the fibronectin present in the culture media. Because of limited availability, the sample sizes used were small. Furthermore, identifying closely matched controls for the studies in brain tissue is particularly difficult. More work is needed to localize further the increases in fibronectin and other ECM molecules in brain tissue and to understand their role in the pathogenesis of SWS.

Studies in rat coronary and retinal tissue $(11,23)$ demonstrate that increased fibronectin expression coincides with blood vessel tube formation and that fibronectin expression decreases during blood vessel maturation. Normal embryonic brain vascularization begins with a primordial plexus of vessels in the subarachnoid space followed by formation of the pial intrinsic plexus and the penetrating vessels. A complex process of vascular remodeling follows to produce a mature network of meningeal and cortical vessels $(24,25)$. Disrupted regulation of fibronectin expression during development could contribute to forming the hypoplastic cortical vessels and the SWS meningeal angioma.

Furthermore, fibronectin has been shown to have potent effects on sympathetic nerve outgrowth and vessel innervation $(26,27)$. Cunha e Sa et al. (28) demonstrated that malformed cortical vessels in SWS are innervated only by noradrenergic sympathetic nerve fibers. In addition, blood vessels in portwine stains have been shown to lack innervation $(29,30)$. We speculate that abnormal regulation of fibronectin expression during vascular development could have a potential role in producing the abnormal vascular innervation found in SWS tissues.

Mitsuhashi et al. (14) demonstrated more prominent fibronectin staining around dilated capillary and venous vessel walls in port-wine skin samples than in controls. These findings were thought to represent secondary changes in the basal lamina of the abnormal port-wine blood vessels, perhaps reflecting the effect of progressive dilation. Our results in SWS port-wine fibroblasts suggest a potential role for fibronectin in the pathogenesis of the lesion, as well. Studies that would compare directly the pathology and gene expression in SWS and non-SWS port-wine stains are presently lacking; however, on the basis of their clinical similarity, the two lesions have been presumed to result from similar pathogenic mechanisms.

In the brain, fibronectin and hexabrachion expression are rapidly induced in response to seizures and are thought to contribute to long-term potentiation $(31,32)$. Increased levels of fibronectin and hexabrachion have also been demonstrated in response to focal CNS injury and may contribute to the formation of glial scarring $(33,34)$. In contrast, after acute ischemic brain injury, fibronectin is thought not to be expressed in the wounded tissue (35). Very little is known regarding fibronectin expression in response to chronic brain hypoxia. The use of fibronectin for the treatment of stroke has been suggested; however, issues of effective delivery and mechanistic questions remain (36).

\section{CONCLUSION}

In conclusion, differences in the expression of fibronectin in port-wine stain fibroblasts and cortical brain samples suggest a role for fibronectin in the pathogenesis and pathology of SWS. Children with SWS can be identified in the first year of life, before the development of fixed and progressive neurologic deficits. Thus, it is imperative that translational studies that may lead to the development of future neuroprotective strategies continue. It is expected that an increased understanding of the underlying pathogenesis and pathophysiology of SWS will eventually suggest new approaches to clinical interventions.

Acknowledgments. We thank the families who made donations of skin and brain tissue. We thank Drs. John Freeman and Eileen P. Vining and the Johns Hopkins Pediatric Epilepsy Brain Bank for providing surgical brain tissue. Tissue was also obtained from the University of Maryland Brain and Tissue Bank for Developmental Disorders, which operates under the NICHD contract \#N01-HD8-3283, and Dr. Peter Black, Brain Tissue Bank at Brigham \& Women's and Children's Hospital. Dr. Diane Chugani provided additional surgical SWS brain tissue. We thank the Sturge-Weber Foundation for its role in coordinating the collection of donated tissue and funding this research. We also thank Larry Frelin and Mollie Lange for providing technical support. We thank the Mental Retardation Developmental Disabilities Research Center (MRDDRC), Neuroimaging Core, 1 PO1 for providing equipment and facilities for our experiments.

\section{REFERENCES}

1. Arzimanoglou AA, Andermann F, Aicardi J, Sainte-Rose C, Beaulieu MA, Villemure JG, Olivier A, Rasmussen Th 2000 Sturge-Weber syndrome: indications and results of surgery in 20 patients. Neurology 55:1472-1479

2. Sujansky E, Conradi S 1995 Sturge-Weber syndrome: age of onset of seizures and glaucoma and the prognosis for affected children. J Child Neurol 10:49-58 
3. Bodensteiner JB, Roach ES 1999 Sturge-Weber syndrome: introduction and overview. In: Bodensteiner JB, Roach ES (eds) Sturge-Weber Syndrome. Sturge-Weber Foundation, Mt Freedom, NJ, pp 1-9

4. Etchevers HC, Vincent C, Le Douarin NM, Couly GF 2001 The cephalic neural crest provides pericytes and smooth muscle cells to all blood vessels of the face and forebrain. Development 128:1059-1068

5. Happle R 1987 Lethal genes surviving by mosaicism: a possible explanation fo sporadic birth defects involving the skin. J Am Acad Dermatol 16:899-906

6. Simonati A, Colamaria V, Bricolo A, Dalla Bernardina B, Rizzuto N 1994 Microgyria associated with Sturge-Weber angiomatosis. Childs Nerv Syst 10:392-395

7. Di Trapani G, Di Rocco C, Abbamondi AL, Caldarelli M, Pocchiari M 1982 Light microscopy and ultrastructural studies of Sturge-Weber disease. Childs Brain 9:23-36

8. Prayson RA, Grewal ID, McMahon JT, Barna PB, Estes ML 1996 Leukocyte adhesion molecules and x-ray energy dispersive spectroscopy in Sturge-Weber disease. J Pediatr Neurol 15:332-336

9. Hungerford JE, Little CD 1999 Developmental biology of the vascular smooth muscle cell: building a multilayered vessel wall. J Vasc Res 36:2-27

10. Risau W, Lemmon V 1988 Changes in the vascular extracellular matrix during embryonic vasculogenesis and angiogenesis. Dev Biol 125:441-450

11. Rongish BJ, Hinchman G, Doty MK, Baldwin HS, Tomanek RJ 1996 Relationship of the extracellular matrix to coronary neovascularization during development. J Mol Cell Cardiol 28:2203-2215

12. Zhao L, Eghbali-Webb M 2001 Release of pro- and anti-angiogenic factors by human cardiac fibroblasts: effects on DNA synthesis and protection under hypoxia in human endothelial cells. Biochim Biophys Acta 1538:273-282

13. Yi M, Ruoslahti E 2001 A fibronectin fragment inhibits tumor growth, angiogenesis, and metastasis. Proc Natl Acad Sci U S A 98:620-624

14. Mitsuhashi Y, Odermatt BF, Schneider BV, Schnyder UW 1988 Immunohistologica evaluation of endothelial markers and basement membrane components in port-wine stains. Dermatologica 176:243-250

15. Barrett T, Cheadle C, Wood WH, Teichberg D, Donovan DM, Freed WJ, Becker KG, Vawter MP 2001 Assembly and use of a broadly applicable neural cDNA microarray. Restor Neurol Neurosci 18:127-135

16. Bouton CM, Hossain MA, Frelin LP, Laterra J, Pevsner J 2001 Microarray analysis of differential gene expression in lead-exposed astrocytes. Toxicol Appl Pharmaco 176:34-53

17. Colantuoni C, Henry G, Zeger S, Pevsner J Accessed September 15, 2001 SNOMAD Standardization and Normalization of MicroArray Data. Available at: pevsnerlab.kennedykrieger.org/snomad.htm

18. Bradford MM 1976 A rapid and sensitive method for the quantitation of microgram quantities of protein utilizing the principle of protein dye-binding. Anal Biochem $72: 248-254$

19. Lee JS, Asano E, Muzik O, Chugani DC, Juhasz C, Pfund Z, Philip S, Behen M, Chugani HT 2001 Sturge-Weber syndrome: correlation between clinical course and FDG PET findings. Neurology 57:189-195
20. Reid DE, Maria BL, Drane WE, Quisling RG, Hoang KB 1997 Central nervous system perfusion and metabolism abnormalities in Sturge-Weber syndrome. J Child Neurol 12:218-220

21. Okudaira Y, Arai H, Sato K 1997 Hemodynamic compromise as a factor in clinical progression of Sturge-Weber syndrome. Childs Nerv Syst 13:214-219

22. Jin KL, Mao O, Nagayama T, Goldsmith PC, Greenberg D 2000 Induction of vascular endothelial growth factor and hypoxia-inducible factor- $1 \alpha$ by global ischemia in rat brain. Neuroscience 99:577-585

23. Jiang B, Liou GI, Behzadian MA, Caldwell RB 1994 Astrocytes modulate retinal vasculogenesis: effects on fibronectin. J Cell Sci 107:2499-2508

24. Plate KH 1999 Mechanisms of angiogenesis in the brain. J Neuropathol Exp Neurol 58:313-320

25. MacDonald RL, Johns LM 1999 Developmental vascular embryology of the central nervous system. In: Jafar JJ, Awad IA, Rosenwasser RH (eds) Vascular Malformations of the Central Nervous System. Lippincott Williams \& Wilkins, Philadelphia, pp $47-60$

26. Smith PG, Fan Q, Zhang R, Warn JD 1998 Cellular terrain surrounding sympathetic nerve pathways in the rat orbit: comparisons of orbital connective tissue and smooth muscle cell phenotypes. J Comp Neurol 400:529-543

27. Gavazzi I, Boyle KS, Cowen T 1996 Extracellular matrix molecules influence innervation density in rat in rat cerebral blood vessels. Brain Res 734:167-174

28. Cunha e Sa M, Barroso CP, Caldas MC, Edvinsson L, Gulbenkian S 1997 Innervation pattern of malformative cortical vessels in Sturge-Weber Disease: an histochemical, immunohistochemical, and ultrastructural study. Neurosurgery 41:872-877

29. Rydh M, Malm M, Jernbeck J, Dalsgaard C 1991 Ectatic blood vessels in port-wine stains lack innervation: possible role in pathogenesis. Plast Reconstr Surg 87:419421

30. Smoller BR, Rosen S 1986 Port-wine stains: a disease of altered neural modulation of blood vessels? Arch Dermatol 122:177-179

31. Hoffman KB, Pinkstaff JK, Gall CM, Lynch G 1998 Seizure induced synthesis of fibronectin is rapid and age dependent: implications for long-term potentiation and sprouting. Brain Res 812:209-215

32. Ferhat L, Chevassus-au-louis N, Khrestchatisky M, Ben-ari Y, Represa A 1996 Seizures induce tenascin-C mRNA expression in neurons. J Neurocytol 25:535-546

33. Smith GM, Hale JH 1997 Macrophage/microglia regulation of astrocytic tenascin: synergistic action of transforming growth factor- $\beta$ and basic fibroblast growth factor. J Neurosci 17:9624-9633

34. Hertel M, Tretter Y, Alzheimer C, Werner S 2000 Connective tissue growth factor: a novel player in tissue reorganization after brain injury? Eur J Neurosci 12:376-380

35. Hamann GF, Okada Y, Fitridge R, del Zoppo GJ 1995 Microvascular basal lamina antigens disappear during cerebral ischemia and reperfusion. Stroke 26:2120-2126

36. Mosher DF 2001 A role for fibronectin in self-repair after ischemic injury. Nat Med $7 \cdot 290-292$ 